\title{
Model of Electronic Office for a Graphic Disciplines Teacher
}

\author{
Yskak A.Nabi ${ }^{{ }^{*}}$ \\ ${ }^{1}$ Consulting and Methodical Centre, Astana city, Kazakhstan \\ *Nabi Yskak, E-mail: inabi@yandex.ru
}

Received: December 7, 2016 Accepted: December 19, 2016 Online Published: December 21, 2016

doi:10.22158/wjer.v4n1p92

URL: http://dx.doi.org/10.22158/wjer.v4n1p92

\begin{abstract}
This work aims at development of a model of electronic office for a graphic disciplines teacher and its study. Method: modeling is used as main method. Results: on a basis of analysis of the notions "model" and "modeling" is revealed the form and content of the model of an e-office for a graphic disciplines teacher; the model is developed as a unity of the parameters: input, processing and output; the content of all parameters is revealed; a variant of a mockup is given; the model is study on conformity by requirements to the models. Conclusion: developed model correspond to requirements to the models and perhaps is realized in a computer program form.
\end{abstract}

\section{Keywords}

graphic disciplines teacher, modeling, model, Republic of Kazakhstan, e-office

\section{Introduction}

In Kazakhstan by the year 2020, $90 \%$ of educational organizations will use electronic learning (e-learning). Potential of e-learning recourses will create preconditions for its practical realization in the course of graphic disciplines. However, the problems of graphic training in the system of postgraduate education (masters, $\mathrm{PhD}$, professional development of graphic disciplines teachers) in the environment of implementation of e-learning are not solved. Informatization of the education system is in need of investigating of e-learning system introduction problems at the level of development of theoretical and methodological bases.

Analysis of international experience shows that in the learning process becomes an important competence-based approach in which the knowledge and competency obtained by the trainees are orientated towards the professional and personal preparedness, which is the result of education. This preparedness can be formed in the process of mastering the educational program in the school, as well as in the process of independent learning, including the use of opportunities offered by the new technologies, especially information and communication technologies. In accordance with the program document "Kazakhstan-2050" (Strategy "Kazakhstan-2050", 2012) it is expected to implement modernization of teaching methods and actively develop the online education systems. 
In this connection a task was set to develop a model of electronic office for the teacher based on the example of graphic disciplines teacher in the form of an online system, which is a computer program that provides a high level of interactivity between trainee and computer.

\section{Methods}

One of the most promising application areas of applied cybernetics in the social sciences is modeling with use a computer. Modeling method is used widely for conducting of different research types. Scientific modeling is the process of generating abstract, conceptual, graphical or mathematical models. Science offers a growing collection of methods, techniques and theory about all kinds of specialized scientific modeling. In the broader sense, modeling is a scientific discipline that has aim: the study of methods of construction and use of models. Modeling is:

- the construction of models of real existing objects (things, phenomena's, processes);

- the replacement of a real object by its suitable copy—imitation;

- the research of knowledge objects on their models (Belyaev, Lysenko, \& Malinina, 2006).

According to Tom Ritchey (2012) "By their very nature, models and modeling are subjects of study in virtually every area of science: from mathematics, physics, engineering and computer science, to psychology, sociology and the philosophy of science... Here is my take on it, at least as concerns scientific modeling (to be sure, a qualification which is not totally clear)".

1. It would provide a real definition of the concept of a model, i.e., an operational definition that tells us something about how models are developed and how they operate...

2. This definitional framework should be as general as possible...

3. The operational definition should either include, or make it possible to abstract, a set of properties (or parameters) which indicate how models do their work, and by which different modeling methods can be classified, exemplified, compared and otherwise scrutinized.

4. It would provide a framework for identifying the requirements for the successful application of different modeling methods for different modeling tasks and for different objects of scientific enquiry...

5. It should give us a basis for treating models and modeling...

6. Finally, as a corollary to all of the above, it would provide a common modeling language and terminology" (pp. 1-2).

Modeling is the study of an object by the method of constructing and studying its model. It is implemented with a specific purpose and consists of replacing the study of the original with the study of a model and widely used in science for representation and transformation of objects, phenomena or processes that do not yet exist or for some reason unavailable. The developed model allows operating by them, to determine stable properties, the individual essential aspects of designed objects, phenomena and processes, to highlight and to expose them to a more thorough logical analysis. Modeling object is a broad concept that includes objects of animate or inanimate nature, processes and phenomena of 
reality. The main task of modeling process in socio-pedagogical researches is a selection of a most true and correct model of the original and the transfer of research results on the original. Modeling in socio-pedagogical researches is closely connected with such categories as abstraction, analogy, hypothesis, etc.

Modeling as a research method has long ago proved its effectiveness in the study of sociological processes, including the educational process. Modeling in pedagogy helps graphically displaying the complexity of the educational process and contributes to the solution of arising problems, therefore, it is considered to be one of the primary and most effective pedagogical tools. As you know, pedagogical modeling has the following types: conceptual, systematic, procedural, notional, experimental, etc.

\section{Results}

\subsection{Structure of the Model}

Model (from Latin "modulus"- a measure, a sample) is a type, a mark, a sample of construction of anything; a scheme, a picture or a description of a phenomenon or process in nature and society; a specially developed form of the object for reproducing certain characteristics of the authentic object. As a research tool, it must reflect the signs, the facts and the relationships in certain areas of knowledge and presents approximate, limited notion of the structure and functioning of a certain study object. In general terms, the model refers as the image, description, diagram, and representation of object or objects system used under certain conditions as his substitute or representative. Model is a representation of the object in some form than is distinguished from forms of its real existence. Usually the model is a tool that assists us in the explanation of the understanding or improvement of objects and systems can be an exact copy of the object, or to reflect some characteristic properties in an abstract form. The study of objects of knowledge by means of models is called the modeling process.

Models are of central importance in many scientific contexts... Scientists spend a great deal of time building, testing, comparing and revising models, and much journal space is dedicated to introducing, applying and interpreting these valuable tools. In short, models are one of the principal instruments of modern science (Frigg, Roman, Hartmann, \& Stephan, 2012). Model is a new object that reflects the essential features of the studied object, phenomenon or process, therefore it is either a representation (real, imaginary or figurative), or a description of some object properties (Belyaev et al., 2006).

As noted by Yadrovskaya (2013), strict and unequivocal models classification impossible to build, since the model serves only as a means of knowledge and in its pure form does not exists (p. 139). Most scientists divide the models into the ideal and the material. The ideal models, for example, from the point of view of the method of their construction, are divided into figurative, symbolic and figurative-symbolic. Belyaev et al. (2006) consider that a diversity of models is divided into three classes:

1. The material (natural) model;

2. Abstract model; 
3. Informational model - a description of the modeling object in one of the information encoding languages (a verbal description, diagrams, drawings, maps, images, scientific formulas, programs, etc.). In our opinion the informational model for programs can be is called by a simulation model. By its nature, the simulation model is significant and real model and has the traits of both physical (material) and mathematical (symbolic) models (Encyclopedically dictionary, 2013). Simulation modeling is the process of creating and analyzing of a digital prototype of a physical model for to predict its performance in the real world. It is used to help designers and engineers understand whether, under what conditions, and in which ways a part could fail and what loads it can withstand.

We apply the modeling for the purpose of reflecting in the future model the essential, defining connections, identifying its innovativeness and marking out the ways for further research. As it was shown in our previous works, the model can be represented in the unity of the parameters: input, processing (of the operation, process parameter, etc.) and output, with indicating of feedback between the input and output parameters as the conditions of reflection.

\subsection{Content of the Model of E-Office for the Graphic Disciplines Teacher}

We share the opinion of some scientists that, beside the ideal and the material models, it is possible to develop the simulation models. This is essential because in our case, in one model we connect all three types of models, i.e., develop a comprehensive model. The most acceptable form of the model is the form that is shown in Figure 1.

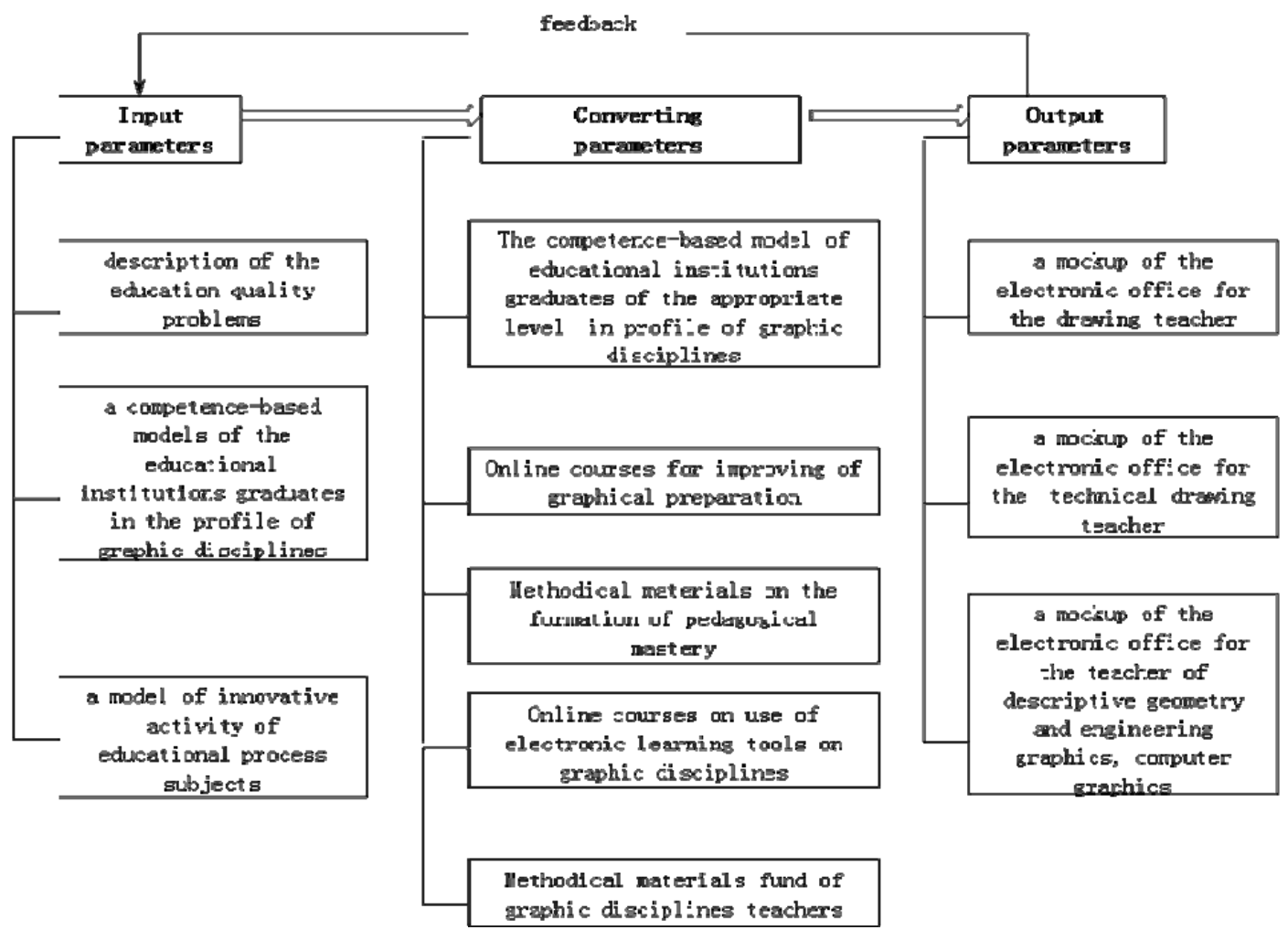

Figure 1. Structural Model of E-Office for the Graphic Disciplines Teacher 
Let us reveal the contents of the model according on the parameters specified in the upper part of the scheme.

Input parameters include:

1) A model of the description of the education quality problems. This is determined by the fact that they generate a search of innovative approaches to the improvement of the education quality. These problems are identified in many of our works, for example, in the monograph (Nabi, 2014) and paper (Nabi et al., 2016). However, they may require additions, so the list of these problems we took from the official document (State program, 2016). There, in the section "Higher and postgraduate education", the following problems are specified: educational programs do not meet the expectations of employers, graduate employment rate in the first year after graduation remains low (71\%), graduates of pedagogical specialties are not oriented towards the use of the new learning technologies in educational practice, etc.;

2) A competence-based models of the educational institutions graduates in the profile of graphic disciplines. These models were developed by us in (Nabi, Tokmagambetov, Tolbayev, \& Ibishev, 2016). Description of learning results (competence-based models from the perspective of graphical disciplines) of the educational system graduates is made on the basis of the B. Bloom's taxonomy and of the Dublin descriptors;

3) A model of innovative activity of educational process subjects. The model was developed by us in the article (Nabi, Chaprova, \& Buganova, 2016). In this model, on vertically the components sequence is located in accordance with the definition of educational innovations: the motive, the purpose, the process and the result of the transforming educational activity of educational process subjects. Horizontally, we located the characteristics of these components within the innovative activity of subjects of educational process - $\mathrm{a}$ teacher and a student. As we can observe, the models are ideal content-wise and are figurative form-wise.

Converting parameters form the design model. They are divided into the following blocks:

1) block 1 . The competence-based model of educational institutions graduates of the appropriate level in profile of graphic disciplines. The allocation of levels is required, due to the fact that the developed model of e-office is multi-leveled, in accordance with the levels of e-learning described in (Nabi, 2015);

2) block 2. Online courses for improving of graphical preparation allow the users of office to develop these competencies. Electronic versions of textbooks on graphic disciplines will be placed here.

3) block 3. Methodical materials on the formation of pedagogical mastery. They will be collected from various sources and are structured by teaching levels;

4) block 4. Online courses on use of electronic learning tools on graphic disciplines. They will contribute to the study and practical application of electronic textbooks and digital educational resources. Here, the teaching level will also be taken into account;

5) block 5. Methodical materials fund of graphic disciplines teachers. It is kind of a forum in which Published by SCHOLINK INC. 
graphic disciplines teachers will share their experiences, offer developed methodological materials for discussion and use in the educational process.

The output model parameters represent the material model, if embodied in the form of a computer program. They also have 3 levels:

1) the mockup of the electronic office for the drawing teacher;

2) the mockup of the electronic office for the technical drawing teacher;

3) the mockup of the electronic office for the teacher of descriptive geometry and engineering graphics, computer graphics.

Figure 2 shows a variant of the mockup of the e-office for the drawing teacher. The interface of mockup can be changed, but it needs to match the content of the project model. The mockup is designed in Kazakh language; the picture lists the location of the blocks in English.

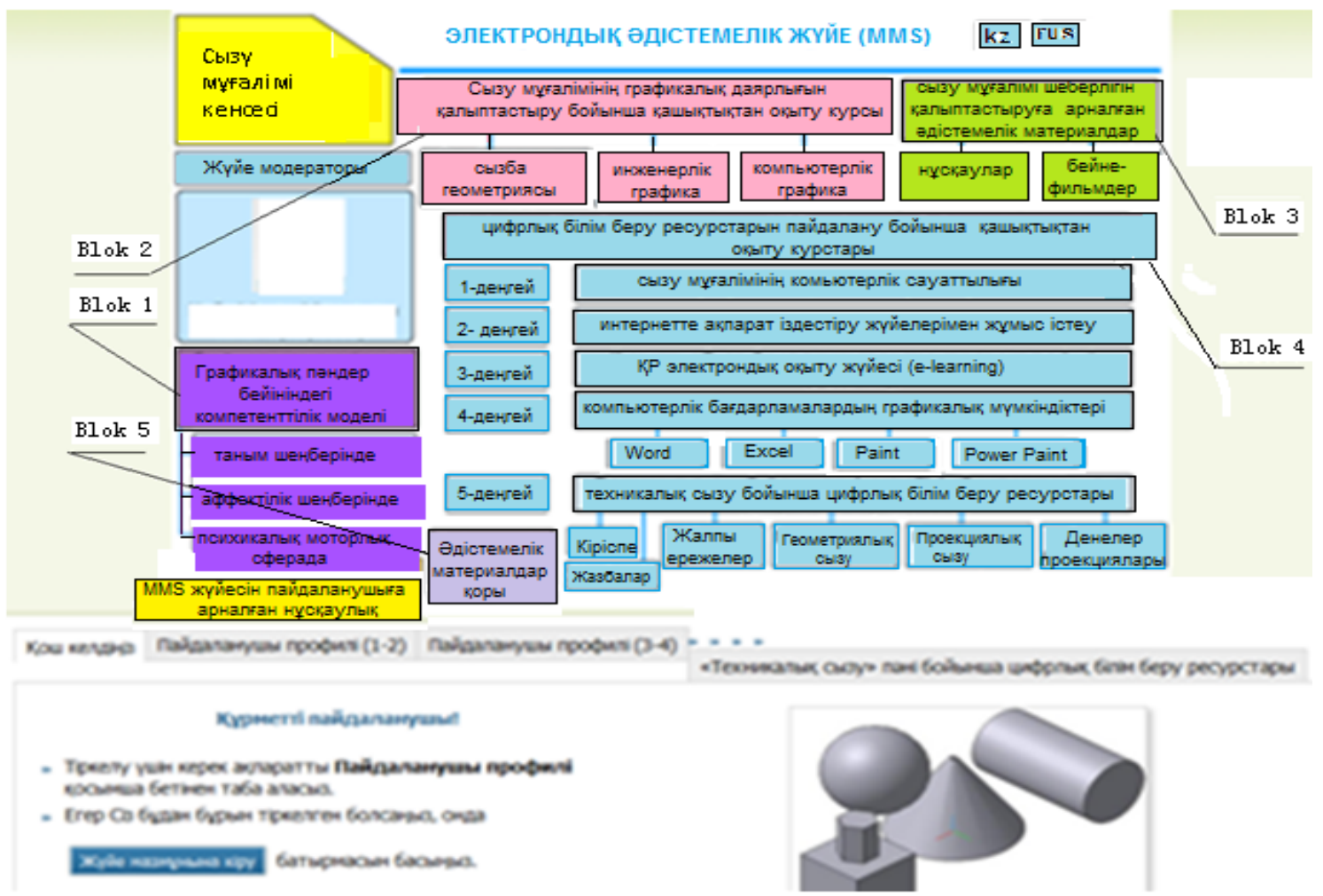

Figure 2. Variant of the Mockup of the E-Office for the Drawing Teacher

\section{Discussion}

Tom Ritchey (2012) asks a question "What is a scientific model?" and writs: “...the general notion of a scientific model is so broad and all-encompassing that any attempt to give it both a complete and (logically) consistent definition may be futile. ...I instead put forward what I consider to be two necessary criteria for something to be a scientific model... The two criteria are:

A. A scientific model must contain two or more mental constructs that can serve as variables, i.e., dimensions which (at least potentially) can support a range of values or states... 
B. One must be able to establish relationships either between the variable entities as such, or between the values of the value ranges within the variables (e.g., causal, probabilistic, logical, etc.)" (p. 5). The author admits that "... this in itself is a very general and abstract notion of the concept of 'model' - and is certainly not the only one that can be formulated..." (p. 5). In accordance with this we adduce the more wide requirements to the models.

Version 1

1. Adequacy — enough accurate reflect of object properties;

2. Completeness - providing by the recipient all necessary information about the object;

3. Flexibility-the ability of reproduction a variety situations;

4. The working hours of the development must be acceptable for the constraints time and software.

\section{Version 2}

The first requirement is it's inherently that is a sufficient degree of harmonization of created model with the environment; the created model must be agreed with the cultural environment in which it will operate. Another model's aspect consists in what not only the model must be adapted to the environment, but the environment must be adapted to future system model.

The second requirement is model's simplicity. The model's simplicity is its inevitable feature.

Finally, the third requirement to the model is its adequacy. The model adequacy means that it is sufficiently complete, exact and true.

Version 3

The model must be actually. This means that the model must be focused on current, upcoming, important problems. The model must be effective. This means that the obtained modeling results can find successful application. The model must be reliable. This requirement is closely related with the notion of adequacy. The model must be economical. This means that the effect of the use of modeling results exceeds the expenses of resources for its creation and study.

Version 4

Basic requirements to the models are:

- visualize of construction (graphical plastics, mockup...);

- visibility of the fundamental properties and relations;

- availability it's for research or reproduction;

- simplicity of research and reproduction;

- maintaining of the information that is contained in the original and obtaining new information.

Apparently, the models do not have the recognized requirements; however the adduced requirements are interrelated. It can see from Figure 3, on which a tie between close by meaning requirements is shown using lines. 


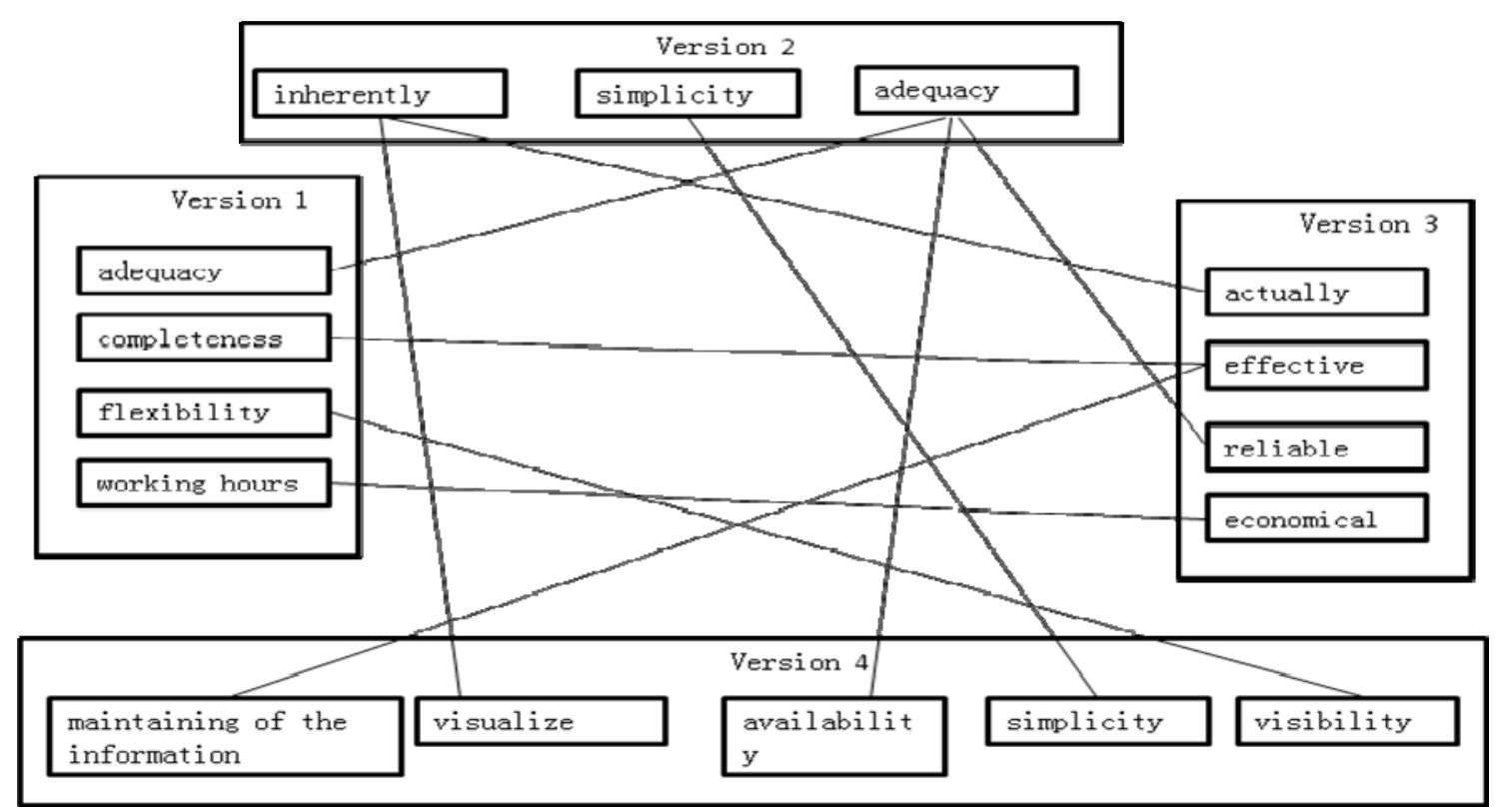

Figure 3. Interrelation between Requirements

Now we examine the developed model for conformity with these requirements.

The model is inherently, because it is designed with the pedagogical design laws, so it will function in the pedagogical environment. However, to ensure the second side of inherently the graphic disciplines teachers must to teach how to use the model.

The model is simple, because it is presented in the form of a compact scheme. However, it is full, as it covers three groups of parameters, each of which includes a sufficient number of elements (modules, blocks).

The model is exact, as it excluded irrelevant factors; it corresponds to purpose of modeling. Question of the model truthfulness (validity) is remained an open. It will be by the object of further research.

\section{Conclusion}

Thus, the realization of the model of the e-office for the graphic disciplines teacher will enhance the possibility of the inculcation of e-learning in Kazakhstan.

The analysis of the notions "model" and "modeling" provided a possibility to discover that the developed model will be comprehensive and will consist of ideal, material and simulation models.

The developed model reflects an essential, defining ties, shows its innovativeness and outlines the ways for further research, namely towards realization in a computer program form.

\section{References}

Belyaev, M. A., Lysenko, V. V., \& Malinina, L. A. (2006). Foundations of computer science: A textbook for high school.-M. Higher education (p. 352). (In Russian)

Encyclopedically dictionary by psychology and pedagogy. (2013). (In Russian)

Published by SCHOLINK INC. 
Frigg, R., \& Hartmann, S. (2012). Models in Science. In Zalta, \& N. Edward (Ed.), The Stanford Encyclopedia of Philosophy. Models in Science. First published Mon Feb 27, 2006; substantive revision Mon Jun 25, 2012.

http://www.studopedia.su

http://www.dl.acm.org

http://www.en.wikipedia.org

http://www.bourabai.ru

http://www.englishschool12.ru

Nabi, Y. (2014). The quality assurance system in higher education: Designing on a base of the EFQM model: The monograph (p. 21). Deutschland, Saarbrucken, Palmarium Academic Publishing. (In Russian)

Nabi, Y. A. (2015). Classification of levels of inculcation of e-learning in Kazakhstan/Actual problems of humanitarian and natural Sciences. Journal of scientific publications, 7(78), 141-143. (In Russian)

Nabi, Y. A., Zhaxylykova, N. E., Kenbaeva, G. K., Tolbayev, A., \& Bekbaeva, Z. N. (2016). Education quality in Kazakhstan in content of competence-based approach. International journal of environmental \& science education, 11(10), 3423-3435.

Nabi, Y., Tokmagambetov, A., Tolbayev, A., \& Ibishev, U. (2016). Competence-based models of educational institutions graduates in the profile of graphic disciplines (pp. 110-121). The collection includes 3rd International scientific-practical conference "Innovations in science, technology, and the integration of knowledge" Held by SCIEURO in London 23-28 February 2016. (In Russian)

Nabi, Y. A., Chaprova, G. G., \& Buganova, S. N. (2016). Model of innovative activity of educational process subjects (No. 4, Vol. 61, pp. 41-47). Personality, family and society: Questions of pedagogy and psychology: Collection of articles on materials of the LXIII international research and practice conference. Novosibirsk: SibAK. (In Russian)

Ritchey, T. (2012). Outline for a Morphology of Modelling Methods. Contribution to a General Theory of Modelling (Vol. 1, No. 1). Acta Morphologica Generalis.

State program of development of education and science of the Republic of Kazakhstan for the years 2016-2019. (2016). Astana, 2016. Retrieved from http://www.edu.gov.kz/ (In Kazakh)

Strategy "Kazakhstan-2050": New political course of the established state. (2012). The message of the President of the Republic - Leader of the nation N. A. Nazarbayev to people of Kazakhstan. Retrieved from http://www ortcom.kz (In Kazakh)

Yadrovskaya, M. V. (2013). Models in pedagogy, 366 (Issue No 366). The Bulletin of Tomsk state University. (In Russian) 